\title{
Reichen Sie jetzt Ihr Abstract ein!
}

Noch bis zum 1. Mai 2021 können Sie Ihr Abstract für die 58. Jahrestagung der Gesellschaft für Pädiatrische Radiologie einreichen.

Die Schwerpunktthemen in diesem Jahr sind unter anderem „State of the Art and Future Directions“ und „AI \& IT based reporting“. Zu ersterem wird vorgestellt, was aktuell "hot“ ist in Wissenschaft und Klinik, beispielsweise Vorträge zu Atemgasanalysen von Intensivpatientinnen und -patienten, mit denen Infektionen früher erkannt werden können. Zum aktuellen Thema „Artifficial Intelligence“ wird es

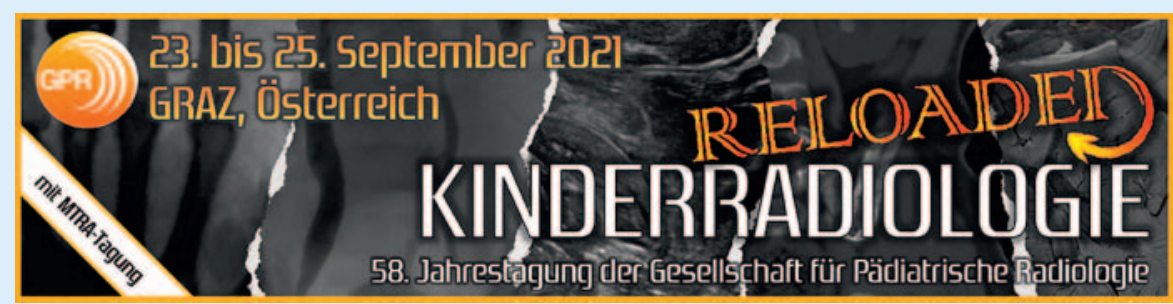

unter anderem eine Simulation geben, die zeigt, wie solch ein künstliches System lernt, wann es damit fertig ist und was man als Kinderradiologin und Kinderradiologe davon erwarten kann.
Alle weiteren Informationen zur Abund zur Anmeldung finden Sie auf gpr-jahrestagung.de stracteinreichung, zum Programm 